\title{
Clinical utility of non-invasive prenatal testing in pregnancies with ultrasound anomalies
}

\author{
L. BEULEN ${ }^{1}$, B. H. W. FAAS ${ }^{2}$, I. FEENSTRA ${ }^{2}$, J. M. G. VAN VUGT ${ }^{1}$ and M. N. BEKKER ${ }^{1,3}$ \\ ${ }^{1}$ Department of Obstetrics and Gynaecology, Radboud University Medical Center, Nijmegen, The Netherlands; ${ }^{2}$ Department of Human \\ Genetics, Radboud University Medical Center, Nijmegen, The Netherlands; ${ }^{3}$ Wilhelmina Children's Hospital Birth Center, Utrecht \\ University Medical Center, Utrecht, The Netherlands
}

KEYWORDS: clinical utility; cohort study; etiology; genetic testing; non-invasive prenatal testing; prenatal diagnostic testing; ultrasound anomalies

\begin{abstract}
Objective To evaluate the application of non-invasive prenatal testing (NIPT) as an alternative to invasive diagnostic prenatal testing in pregnancies with abnormal ultrasound findings.
\end{abstract}

Methods This was a retrospective analysis of 251 singleton and multiple pregnancies at high risk for fetal chromosomal abnormality based on findings at sonographic examination, in which NIPT was performed as a first-tier genetic test. NIPT was performed by massively parallel sequencing of cell-free DNA in maternal plasma, allowing genome-wide detection of whole-chromosome, as well as partial, autosomal aneuploidy. Sex chromosomes were not analyzed, according to the current protocol in Dutch laboratories.

Results NIPT was performed at a median gestational age of 20 weeks, indicated by the presence of multiple congenital anomalies $(\mathrm{n}=13)$, isolated structural anomalies $(\mathrm{n}=57)$, increased nuchal translucency $\geq 3.5 \mathrm{~mm}$ $(\mathrm{n}=58)$, soft markers $(\mathrm{n}=73)$, growth restriction $(\mathrm{n}=40)$ and other anomalies $(\mathrm{n}=10)$. NIPT results were normal in $224(89.2 \%)$ pregnancies, inconclusive in one $(0.4 \%)$ and abnormal in $26(10.4 \%)$. Most genetic aberrations detected by NIPT were common whole-chromosome aneuploidies: trisomy $21(\mathrm{n}=13)$, trisomy $18(\mathrm{n}=6)$ and trisomy $13(\mathrm{n}=3)$. Four further NIPT results were abnormal; one was suspected of being confined placental mosaicism and one was of maternal origin. In those with normal NIPT results, sonographic follow-up or examination of the newborn indicated the need for diagnostic genetic testing in 33/224 (14.7\%) pregnancies. Clinically relevant genetic aberrations were revealed in $7 / 224$ (3.1\%) cases, two of which were whole-chromosome aneuploidies: trisomy 13 and monosomy X. As sex chromosomal aberrations are not included in NIPT analysis, the latter cannot be considered a false-negative result. Other discordant findings were subchromosomal aberrations $(<20$ megabases, $\mathrm{n}=2)$ and monogenic aberrations $(\mathrm{n}=3)$.

Conclusions NIPT should not be recommended for genetic evaluation of the etiology of ultrasound anomalies, as both resolution and sensitivity, or negative predictive value, are inferior to those of conventional karyotyping and microarray analysis. Nonetheless, some pregnant women consider NIPT to be an acceptable alternative to invasive diagnostic testing. (c) 2016 The Authors. Ultrasound in Obstetrics \& Gynecology published by John Wiley or Sons Ltd on behalf of the International Society of Ultrasound in Obstetrics and Gynecology.

\section{INTRODUCTION}

Pregnant women at high risk for fetal chromosomal abnormality based on findings at sonographic examination are offered prenatal genetic testing. Genetic evaluation enables determination of the etiology of the ultrasound anomaly, overall fetal prognosis and risk of recurrence in future pregnancies. The information obtained could facilitate prospective parents' reproductive decision-making when confronted with the choice between terminating pregnancy or continuing pregnancy and preparing themselves for the birth of a child with a physical and/or intellectual disability.

In cases with ultrasound anomalies, fetal genotyping is usually performed by quantitative fluorescent polymerase chain reaction (QF-PCR) of fetal DNA for rapid diagnosis of (an)euploidy of chromosomes 13, 18, 21 and the sex chromosomes. If QF-PCR results are normal, microscopic G-band karyotyping has long been the standard approach to detect chromosomal aberrations at a resolution

Correspondence to: Dr L. Beulen, Department of Obstetrics and Gynaecology (791), Radboud University Medical Center, P.O. Box 9101, 6500 HB Nijmegen, The Netherlands (e-mail: Lean.Beulen@Radboudumc.nl) 
of 5-10 megabases (Mb). At present, chromosomal microarray analysis is recommended instead of, or as an adjunct to, conventional karyotyping, as it allows genome-wide analysis at a much higher resolution (up to 1 kilobase $(\mathrm{kb})$ ), revealing clinically significant unbalanced submicroscopic aberrations ${ }^{1-3}$. However, these techniques all require fetal tissue obtained by an invasive diagnostic procedure, i.e. chorionic villus sampling or amniocentesis. For a considerable number of pregnant women at high risk for fetal chromosomal abnormality, the associated procedure-related risk of miscarriage is a reason to decline invasive diagnostic testing.

The development of non-invasive prenatal testing (NIPT) by massively parallel sequencing (MPS) of cell-free DNA in maternal plasma provides an alternative for the detection of fetal genetic aberrations with the increased safety of performing maternal blood sampling instead of an invasive diagnostic procedure. NIPT detects common whole-chromosome aneuploidy such as trisomy 21 (T21, Down syndrome), trisomy 18 (T18, Edwards syndrome) and trisomy 13 (T13, Patau syndrome) with high sensitivity and specificity ${ }^{4}$. The non-invasive detection of subchromosomal copy-number variants (CNVs), i.e. microdeletions and microduplications, at a resolution comparable with that of microarray analysis has been shown to be feasible ${ }^{5}$. However, routine implementation of the latter technique is hampered by its requirements for significantly deeper sequencing, which is costly ${ }^{6}$. Furthermore, extensive validation is needed to determine accurately its detection rate and false-positive rate, which is difficult owing to the low prevalence of specific genetic aberrations. Nonetheless, some pregnant women at high risk for fetal chromosomal abnormality based on findings at sonographic examination already consider NIPT an acceptable alternative to invasive diagnostic testing.

This study aimed to evaluate the application of NIPT as an alternative to invasive diagnostic testing for the detection of fetal genetic aberrations in pregnancies with ultrasound anomalies.

\section{METHODS}

\section{Study design and subjects}

This was a retrospective study of all pregnant women at high risk for fetal chromosomal abnormality based on findings at sonographic examination, who underwent NIPT as an alternative to fetal genotyping by QF-PCR and microarray analysis at prenatal diagnostic centers linked to the Network for Prenatal Diagnosis Nijmegen, between April 2014 and November 2015. Ethical approval was granted by the medical ethics committee of the Radboud University Medical Center, Nijmegen, The Netherlands.

\section{Counseling}

Pregnant women at high risk for fetal chromosomal abnormality based on sonographic examination were offered prenatal genetic testing. As part of the standard care offered in the prenatal diagnostic centers linked to the Network for Prenatal Diagnosis Nijmegen, all prospective parents included in the cohort received thorough pretest counseling on the test characteristics and potential benefits and disadvantages of different modalities for prenatal genetic testing. Invasive diagnostic testing was offered as the first-tier genetic test, utilizing both QF-PCR and chromosomal microarray analysis, thereby providing maximum information and a definitive diagnosis. Counseling included information on the invasive diagnostic procedure needed to obtain fetal tissue and the associated procedure-related risk of miscarriage, i.e. $0.5 \%$ for chorionic villus sampling and $0.3 \%$ for amniocentesis.

Counseling on NIPT included information on the test being validated for the detection of only T21, T18 and T13, thus offering limited information compared with invasive diagnostic testing. Pregnant women and their partners were informed that other potentially clinically relevant abnormal test results besides T21, T18 and T13 would be discussed with them. Furthermore, all abnormal test results would have to be confirmed by invasive diagnostic testing, especially when the results would influence management of their pregnancy. Those who decided to have NIPT as an alternative to fetal genotyping by QF-PCR and microarray analysis provided written informed consent for the application of NIPT as a first-tier genetic test.

\section{Genetic testing}

For NIPT, maternal blood samples were obtained at one of five diagnostic centers linked to the Network for Prenatal Diagnosis Nijmegen. All samples were then processed and analyzed at the Department of Human Genetics of the Radboud University Medical Center in Nijmegen, as described previously ${ }^{7,8}$. Briefly, samples underwent centrifugation for plasma separation, followed by manual extraction and MPS of cell-free DNA from maternal plasma. MPS entailed either single-end 50-bp sequencing on a SOLiD 5500 XL Genetic Analyzer (Life Technologies, Foster City, CA, USA) or single-end 75-bp sequencing on a NextSeq 500 desktop sequencer (Illumina, San Diego, CA, USA). After sequencing, reads were mapped to the hg19 reference genome. Samples were tested for fetal chromosomal aberrations using WISECONDOR, a within-sample comparison algorithm using GC-corrected 1-Mb genomic bins ${ }^{9,10}$. With this algorithm, both whole-chromosome, as well as partial, aneuploidy can be detected. A whole-chromosome fetal trisomy or monosomy is considered detected when at least $50 \%$ of the bins of a chromosome are aberrant. Using low sequence coverage $(0.1-0.5 \times)$, aberrations smaller than $20 \mathrm{Mb}$ cannot be detected reliably owing to natural fluctuations of read-depth frequencies along the genome. Smaller aberrations are, therefore, considered only if visual inspection of the plots strongly suggests a fetal genetic aberration. Currently, in Dutch laboratories, fetal gender and sex chromosomal aberrations are not analyzed when performing NIPT. Furthermore, fetal fraction is 
not determined. Instead, it is assumed that the blood sample contains sufficient cell-free fetal DNA to allow the identification of fetal chromosomal aberrations.

If prenatal or postnatal diagnostic testing was performed, QF-PCR analysis was carried out according to standard procedures. In cases of normal QF-PCR results, genome-wide high-resolution microarray analysis was carried out according to the manufacturer's specifications on an Affymetrix CytoScan HD array platform (Affymetrix, Inc., Santa Clara, CA, USA). Cut-offs for detection criteria for CNVs were set at $20 \mathrm{~kb}$ for gains, $10 \mathrm{~kb}$ for losses and $1250 \mathrm{~kb}$ for regions of homozygosity ${ }^{11}$. Where applicable, parental DNA was analyzed to facilitate the interpretation of abnormal microarray results. If CNVs were inherited from a healthy parent, i.e. parents without physical or neurodevelopmental anomalies, they were classified as most probably benign. Targeted DNA testing for monogenic diseases was performed in adjunct to microarray analysis if indicated.

\section{Data collection}

Medical records were reviewed to extract the following data: maternal age, maternal weight, gravidity, parity, sonographic findings that indicated the need for prenatal genetic testing, gestational age at time of blood sampling for NIPT, results of NIPT, (additional) findings of any follow-up sonographic examination, results of any diagnostic genetic testing and pregnancy outcome, including findings at the newborn examination. Pathogenic aberrations detected by genetic testing were classified as causative findings, unexpected diagnoses or susceptibility loci for neurodevelopmental disorders based on their relationship with findings of the sonographic and/or newborn examination. Aberrations found unintentionally in prospective parents were classified as incidental findings ${ }^{12}$.

\section{RESULTS}

Between April 2014 and November 2015, prenatal genetic testing was performed in 590 pregnant women at high risk for fetal chromosomal abnormality based on sonographic examination. NIPT was applied as the first-tier test for the detection of genetic aberrations in $251(42.5 \%)$ pregnancies. Of these, $230(91.6 \%)$ were singleton and $21(8.4 \%)$ were multiple pregnancies. In all multiple pregnancies, ultrasound anomalies were present in only one of the fetuses when genetic testing was first indicated, thus also when NIPT was performed. Characteristics of the pregnant women included in the cohort are shown in Table 1.

An overview of the findings from NIPT and diagnostic genetic testing in pregnancies with sonographic anomalies is shown in Figure 1, Tables 2-4, Table S1 and (showing multiple gestations only) Table S2. NIPT results were normal in $224(89.2 \%)$ pregnancies, inconclusive in one $(0.4 \%)$ and abnormal in $26(10.4 \%)$.
Table 1 Characteristics of 251 pregnant women with abnormal findings at sonographic examination who had non-invasive prenatal testing (NIPT) as first-tier genetic test

\begin{tabular}{lc}
\hline Characteristic & Value \\
\hline Age (years) & $31(17-44)$ \\
Maternal weight at NIPT $(\mathrm{kg})$ & $69(44-123)$ \\
Singleton pregnancy & $230(91.6)$ \\
Multiple pregnancy & $21(8.4)$ \\
Primigravid & $94(37.5)$ \\
Multigravid & $157(62.5)$ \\
Nulliparous & $119(47.4)$ \\
Parous & $132(52.6)$ \\
GA at NIPT (weeks)* & $20(10-34)$ \\
\hline
\end{tabular}

Data are given as median (range) or $n(\%)$. ${ }^{*}$ Gestational age (GA) had bimodal distribution, with peaks at $12-13$ weeks and at 20-21 weeks.

\section{Abnormal NIPT result}

The majority of genetic aberrations detected by NIPT were whole-chromosome aneuploidies: 13 cases of T21, six cases of T18, three cases of T13 and one case of trisomy 16. Follow-up diagnostic genetic testing was performed in 21 of these 23 pregnancies.

In two cases, the findings of NIPT and diagnostic genetic testing were discordant. In one specific case, prenatal testing was indicated for genetic evaluation of the etiology of multiple structural anomalies present in one fetus of a diamniotic twin pregnancy. No structural anomaly was observed in the other fetus when NIPT was performed at $12+5$ weeks' gestation. NIPT was abnormal, indicating the presence of T21. Follow-up sonographic examination at 17 weeks' gestation revealed an atrioventricular septal defect and absent nasal bone, suggestive of T21, in the fetus without previously detected anomalies. QF-PCR analysis of fetal tissue obtained by amniocentesis confirmed the presence of T21 (detected by NIPT) in this fetus, but also detected T13 (not detected by NIPT) in the other fetus. When NIPT was repeated for research purposes at $17+5$ weeks' gestation, both aneuploidies were detected. The pregnancy was terminated.

In the second case with discordant results, NIPT revealed fetal trisomy 16 , or mosaic thereof, which could be confirmed neither by karyotyping of amniotic fluid nor by fluorescent in-situ hybridization analysis using a probe specific for chromosome 16 (D16Z3). However, postnatal microarray analysis revealed the presence of maternal uniparental disomy of chromosome 16, most probably owing to so-called 'trisomy 16 rescue'. This, in combination with the observed intrauterine growth restriction and preterm birth, led to a suspected diagnosis of confined placental mosaicism. Unfortunately, placental material was not available for testing (Table 2).

In two cases, abnormal NIPT results were not confirmed by diagnostic genetic testing. In one case, a diamniotic twin pregnancy, prenatal testing was indicated because of a high risk for fetal aneuploidy based on prenatal screening by first-trimester combined test 


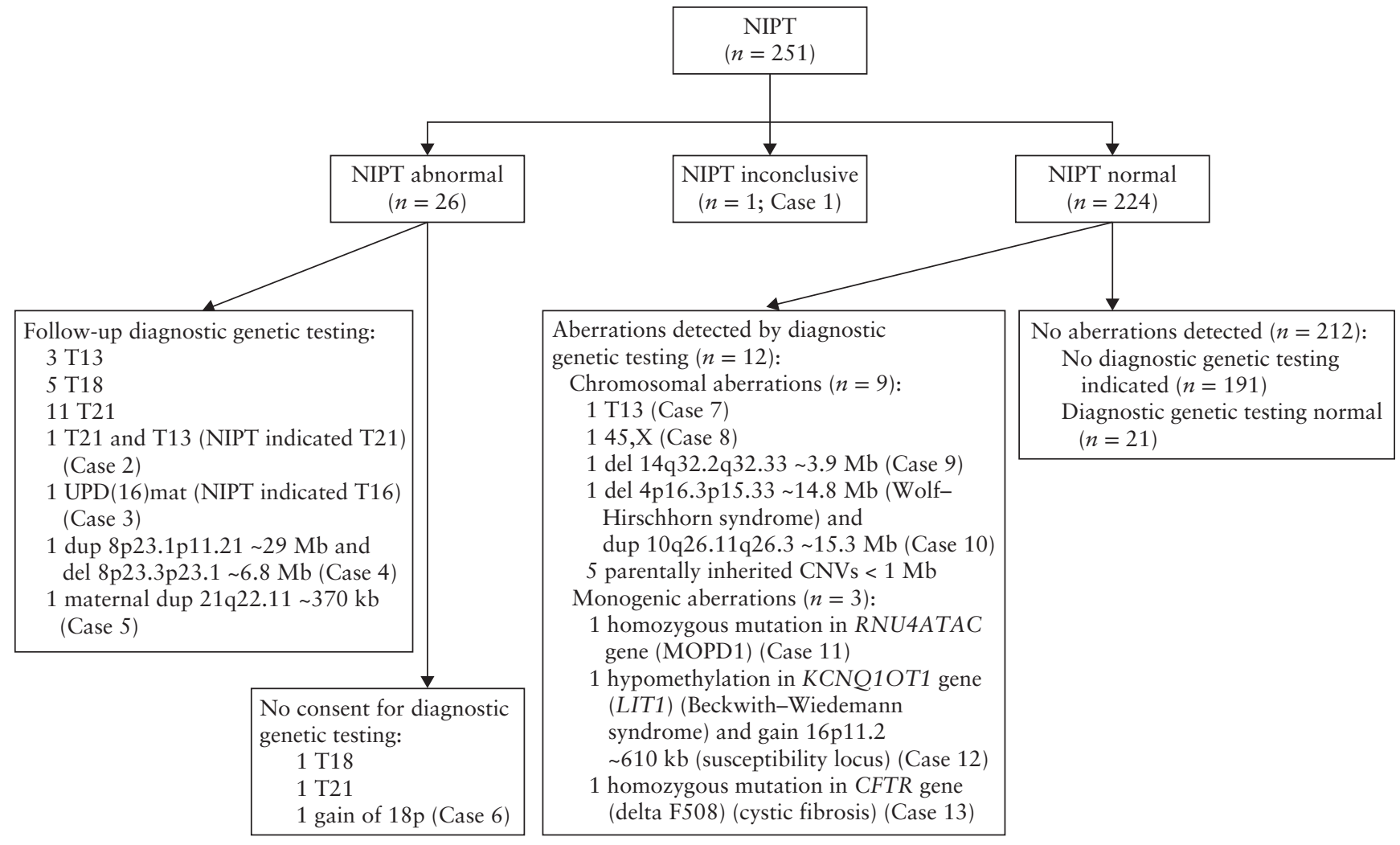

Figure 1 Flowchart of results of non-invasive prenatal testing (NIPT) in 251 pregnancies with ultrasound anomaly. NIPT was by massively parallel sequencing of cell-free DNA in maternal plasma. Diagnostic genetic testing was by quantitative fluorescent polymerase chain reaction, karyotyping, microarray analysis or targeted DNA testing of fetal or maternal tissue. Case 1: genetic testing indicated by polyhydramnios, NIPT did not meet quality criteria, however, visual inspection of plots repeatedly showed suspect chromosome 22 profile. Mother had mild intellectual disability, shortened palate, mild hearing impairment, common variable immunodeficiency. Maternal array was 22q11.21(18,970,562-21,465,660) $\times 1, \sim 2.5$ megabases $(\mathrm{Mb})$. No further genetic testing. Resulted in live birth with no congenital anomaly. Postnatal microarray of newborn revealed $22 \mathrm{q} 11.21(18,648,867-21,798,908) \times 1$ mat, $\sim 2.8 \mathrm{Mb}$. Case 2 : multiple pregnancy, genetic testing indicated by multiple structural anomalies (intrauterine growth restriction, holoprosencephaly, omphalocele, megacystis with bilateral hydronephrosis) in one fetus. No structural anomaly was observed in other fetus. NIPT showed T21. Follow-up ultrasound at 17 weeks' gestation revealed atrioventricular septal defect and absent nasal bone in fetus without previously detected anomalies. Amniocentesis and genetic testing showed 47,XY +21 and 47,XY +13 . Pregnancy was terminated. Cases 3-13 summarized in Tables 2 and 3. CNV, copy number variant; del, deletion; dup, duplication; kb, kilobases; MOPD1, microcephaly osteodysplastic primordial dwarfism Type I; T13, trisomy 13 (Patau syndrome); T16, trisomy 16; T18, trisomy 18 (Edwards syndrome); T21, trisomy 21 (Down syndrome); UPD(16)mat, maternal uniparental disomy of chromosome 16.

(risk: T21, 1:6; T18, 1:22; T13, 1:45), with a nuchal translucency thickness of $3.8 \mathrm{~mm}$ in one fetus. The risk for fetal aneuploidy in the other fetus was not elevated. NIPT was performed at $12+6$ weeks' gestation and indicated the presence of T21. Sonographic follow-up diagnosed intrauterine demise of the affected twin at 14 weeks. Amniocentesis was performed only on the fetus with normal nuchal translucency. QF-PCR results were normal.

In the second case with an abnormal NIPT result not confirmed by diagnostic genetic testing, prenatal testing was indicated by the presence of multiple structural anomalies (semilobar holoprosencephaly, atrioventricular septal defect with hypoplastic left heart) and severe intrauterine growth restriction. Although fetal T18, detected by NIPT, fitted the phenotype, consent for prenatal or postnatal diagnostic testing was not given. The pregnancy ended in intrauterine fetal demise.

Subchromosomal aberrations were detected by NIPT in three other pregnancies (Table 2). Owing to the relatively high region-specific $Z$-score in one case, a maternal origin was suspected, which was subsequently confirmed via microarray analysis of the mother's genomic DNA. Consultation with a clinical geneticist revealed no maternal dysmorphic features, or physical or neurodevelopmental anomaly, therefore the CNV was classified as most probably benign. In another case, NIPT detected accurately an inverted duplication deletion of chromosome $8 \mathrm{p}$. In the third case, a gain of chromosome $18 \mathrm{p}$ was detected, however, consent for prenatal or postnatal diagnostic confirmation was not given. Newborn examination revealed mild dysmorphic features and two small ventricular septal defects that resolved spontaneously.

\section{Normal NIPT result}

Among the 224 pregnancies with normal NIPT results, (additional) findings at sonographic follow-up or newborn examination indicated the need for diagnostic genetic 
Table 2 Overview of cases with abnormal non-invasive prenatal test (NIPT) result other than trisomy 21,18 or 13 , in 251 pregnancies with ultrasound anomaly

\begin{tabular}{|c|c|c|c|c|c|c|c|c|}
\hline \multirow[b]{2}{*}{ Case } & \multirow{2}{*}{$\begin{array}{l}\text { Indication } \\
\text { for genetic } \\
\text { testing }\end{array}$} & \multicolumn{2}{|c|}{ NIPT } & \multicolumn{3}{|c|}{ Diagnostic genetic testing } & \multirow[b]{2}{*}{ Outcome } & \multirow{2}{*}{$\begin{array}{l}\text { Classification } \\
\text { of aberration }\end{array}$} \\
\hline & & Timing & Result & Timing & Test & Result & & \\
\hline \multirow[t]{2}{*}{3} & IUGR & 15 weeks & T16 & 16 weeks & $\begin{array}{l}\text { QF-PCR, } \\
\text { karyotype, } \\
\text { FISH }\end{array}$ & $\begin{array}{l}46, \mathrm{XX} \\
46, \mathrm{XX} \\
\mathrm{D} 16 \mathrm{Z} 3 \times 2\end{array}$ & $\begin{array}{l}\text { Preterm LB with no } \\
\text { congenital } \\
\text { anomaly, extreme } \\
\text { dysmaturity, } \\
\text { perinatal death }\end{array}$ & Causative \\
\hline & & & & Postnatal & Microarray & $\begin{array}{l}\text { arr } 16 \mathrm{p} 13.3 \mathrm{p} 13 \\
2(89,561-8,914,906) \times 2 \\
\text { hmz }=\mathrm{UPD}(16) \mathrm{mat}^{*}\end{array}$ & & \\
\hline 4 & NT $4.7 \mathrm{~mm}$ & 13 weeks & $\begin{array}{c}\text { Gain of } \\
8 \mathrm{p} \dagger\end{array}$ & 16 weeks & $\begin{array}{l}\text { Karyotype, } \\
\text { microarray }\end{array}$ & $\begin{array}{l}\text { 46,XX,del }(8)(\mathrm{p} 23 \\
3 \mathrm{p} 23.1), \operatorname{dup}(8) \\
(\mathrm{p} 23.1 \mathrm{p} 11.21) \\
\text { arr } 8 \mathrm{p} 23.3 \mathrm{p} 23.1(158, \\
049-6,976,182) \times 1 \mathrm{dn}, \\
6.8 \mathrm{Mb}, 8 \mathrm{p} 23.1 \mathrm{p} 11.21 \\
(11,936,001-40 \\
905,009) \times 3 \mathrm{dn} \\
29 \mathrm{Mb}\end{array}$ & TOP & Causative \\
\hline 5 & IUGR & 21 weeks & $\begin{array}{c}\text { Gain of } \\
21 \mathrm{q} \ddagger\end{array}$ & 22 weeks & $\begin{array}{l}\text { Maternal } \\
\text { microarray }\end{array}$ & $\begin{array}{l}\text { arr } 21 \mathrm{q} 22.11(33, \\
522,970-33,889, \\
304) \times 3, \sim 370 \mathrm{~kb} \\
(6 \text { genes })\end{array}$ & $\begin{array}{l}\text { LB with no } \\
\text { congenital } \\
\text { anomaly }\end{array}$ & Incidental \\
\hline 6 & IUGR & 21 weeks & $\begin{array}{c}\text { Gain of } \\
18 \mathrm{p} \$\end{array}$ & $\mathrm{NP}$ & & & $\begin{array}{l}\text { LB, two small VSDs } \\
\text { (resolved } \\
\text { spontaneously), } \\
\text { mild } \\
\text { dysmorphisms }\end{array}$ & \\
\hline
\end{tabular}

"Maternal uniparental disomy of chromosome 16, most likely due to 'trisomy 16 rescue'; placental material not available for testing. $\dagger$ Software analysis showed $30-\mathrm{Mb}$ gain of $8 \mathrm{p}$; visual inspection of plots showed also a (smaller) $8 \mathrm{p}$ terminal loss. ‡Software analysis showed $10-\mathrm{Mb}$ gain of $21 \mathrm{q}$; visual inspection of plots showed relatively high region-specific $Z$-score, therefore, maternal origin was suspected; consultation with clinical geneticist revealed no maternal dysmorphic features or physical or neurodevelopmental anomaly; copy number variant therefore classified as most probably benign. \$Software analysis showed 15 -Mb gain of $18 \mathrm{p}$. FISH, fluorescent in-situ hybridization; IUGR, intrauterine growth restriction; kb, kilobases; LB, live birth; Mb, megabases; NP, not performed; NT, nuchal translucency thickness; QF-PCR, quantitative fluorescent polymerase chain reaction; T16, trisomy 16; TOP, termination of pregnancy; VSD, ventricular septal defect.

testing in $33(14.7 \%)$ cases. Diagnostic testing revealed genetic aberrations in 12 of these pregnancies, seven $(3.1 \%)$ of which were clinically relevant (Table 3$)$. In all other cases, newborn examination was normal or showed congenital anomalies that did not indicate the need for additional genetic testing.

Aside from the previously described case of a diamniotic twin pregnancy with an abnormal NIPT result indicating T21 but missing T13, NIPT did not detect two other common whole-chromosome aneuploidies: one case of T13 and one of monosomy X. As sex chromosomal aberrations were not included in the NIPT analysis, the latter aneuploidy cannot be considered a false-negative result. In two other cases, clinically relevant subchromosomal aberrations were not detected by NIPT: 14.8-Mb 4p16.3p15.33 deletion, associated with Wolf-Hirschhorn syndrome, in combination with 15.3-Mb 10q26.11q26.3 duplication in one case, and a submicroscopic $\sim 3.9-\mathrm{Mb} 14 \mathrm{q} 32.2 \mathrm{q} 32.33$ deletion in another case. Other subchromosomal aberrations detected by postnatal diagnostic testing were parentally inherited CNVs of $<1 \mathrm{Mb}$. As all were inherited from a healthy parent, these were classified as most probably benign and not clinically relevant. Targeted DNA testing confirmed the presence of monogenic aberrations in three other cases. These monogenic aberrations cannot be detected by techniques based on whole-genome analysis of CNVs, such as NIPT or microarray analysis.

If invasive diagnostic testing with QF-PCR and chromosomal microarray analysis had been performed as the first-tier genetic test in all pregnancies included in the cohort, genetic aberrations would have been detected in $12.7 \%$ instead of $10.4 \%$ of all pregnancies, excluding parentally inherited $\mathrm{CNVs}<1 \mathrm{Mb}$ as these were most probably benign and not clinically relevant (Table 4).

\section{DISCUSSION}

Our study evaluates the application of NIPT for prenatal genetic testing in pregnancies at high risk for fetal chromosomal abnormality based on findings at sonographic examination. Our findings show that NIPT should not be recommended as an alternative to invasive diagnostic testing for genetic evaluation of the etiology of ultrasound anomalies. Both resolution and sensitivity, or negative predictive value, are inferior to those of the diagnostic genetic test modalities currently available, 
Table 3 Overview of cases with clinically relevant aberration revealed by diagnostic genetic testing after normal non-invasive prenatal test (NIPT) result in 251 pregnancies with ultrasound (US) anomaly

\begin{tabular}{|c|c|c|c|c|c|c|c|}
\hline \multirow[b]{2}{*}{ Case } & \multirow{2}{*}{$\begin{array}{l}\text { Indication } \\
\text { for genetic } \\
\text { testing }\end{array}$} & \multirow[b]{2}{*}{ Timing } & \multicolumn{3}{|c|}{ Diagnostic genetic testing } & \multirow[b]{2}{*}{ Outcome } & \multirow{2}{*}{$\begin{array}{l}\text { Classification } \\
\text { of aberration }\end{array}$} \\
\hline & & & Timing & Test & Result & & \\
\hline 7 & MCA & 14 weeks & 17 weeks & QF-PCR & $47, X Y+13$ & $\begin{array}{l}\text { IUFD (US at } 17 \\
\text { weeks) }\end{array}$ & Causative \\
\hline 8 & Hydrops fetalis & 12 weeks & Postnatal & QF-PCR & $45, \mathrm{X}$ & $\begin{array}{l}\text { IUFD (US at } 18 \\
\text { weeks) }\end{array}$ & Causative \\
\hline 9 & NT $3.9 \mathrm{~mm}$ & 21 weeks & 32 weeks & Microarray & $\begin{array}{c}14 \mathrm{q} 32.2 \mathrm{q} 32.33(101, \\
220,548-105,080 \\
719) \times 1 \mathrm{dn}, 3.9 \mathrm{Mb}\end{array}$ & $\begin{array}{l}\text { Unilateral } \\
\text { hydrothorax (US } \\
\text { at } 32 \text { weeks), } \\
\text { anal atresia, some } \\
\text { mild } \\
\text { dysmorphisms }\end{array}$ & Causative \\
\hline 10 & IUGR & 23 weeks & Postnatal & Microarray & $\begin{array}{l}\text { 4p16.3p15.33(68, } \\
346-14,875,532) \times 1 \mathrm{dn}, \\
14.8 \mathrm{Mb} \\
\text { (Wolf-Hirschhorn } \\
\text { syndrome) } \\
\text { 10q26.11q26.3(120, } \\
145,796-135,427, \\
144) \times 3 \mathrm{dn}, \\
15.3 \mathrm{Mb}\end{array}$ & $\begin{array}{l}\text { Severe dysmaturity, } \\
\text { microcephaly, } \\
\text { some } \\
\text { dysmorphisms }\end{array}$ & Causative \\
\hline 11 & MCA & 30 weeks & Postnatal & DNA & $\begin{array}{l}\text { Homozygous } \\
\text { pathogenic mutation } \\
\text { in RNU4ATAC gene } \\
\text { (LIT1) (MOPD1) }\end{array}$ & $\begin{array}{l}\text { Severe dysmaturity, } \\
\text { microcephaly, } \\
\text { severe } \\
\text { intracerebral } \\
\text { abnormalities, } \\
\text { VSD, several } \\
\text { dysmorphisms, } \\
\text { bilateral rocker } \\
\text { bottom feet }\end{array}$ & Causative \\
\hline 12 & Omphalocele & 14 weeks & Postnatal & Microarray & $\begin{array}{l}\text { 16p11.2(29,567,296- } \\
30,178,000) \times 3 \mathrm{dn}, \\
610 \mathrm{~kb} \\
\text { (susceptibility locus) } \\
\text { DNA hypomethylation } \\
\text { in KCNQ1OT1 gene } \\
\text { (Beckwith-Wiedemann } \\
\text { syndrome) }\end{array}$ & $\begin{array}{l}\text { Omphalocele, } \\
\text { unilateral duplex } \\
\text { collecting system } \\
\text { and ureterocele } \\
\text { (US at } 18 \text { weeks), } \\
\text { earlobe creases }\end{array}$ & $\begin{array}{l}\text { Susceptibility } \\
\text { locus; causative }\end{array}$ \\
\hline 13 & Echogenic bowel & 21 weeks & 23 weeks* & DNA & $\begin{array}{l}\text { Homozygous } \\
\text { pathogenic mutation } \\
\text { in CFTR gene } \\
\text { (deltaF508) (cystic } \\
\text { fibrosis) }\end{array}$ & TOP & Causative \\
\hline
\end{tabular}

"Parental carrier screening confirmed presence of maternal and paternal pathogenic mutations in CFTR gene (deltaF508). IUFD, intrauterine fetal demise; IUGR, intrauterine growth restriction; kb, kilobases; Mb, megabases; MCA, multiple congenital anomalies; MOPD1, microcephaly osteodysplastic primordial dwarfism Type I; NT, nuchal translucency thickness; QF-PCR, quantitative fluorescent polymerase chain reaction; TOP, termination of pregnancy; VSD, ventricular septal defect.

i.e. conventional G-band karyotyping and chromosomal microarray analysis.

NIPT for the detection of fetal genetic aberrations in pregnancies with ultrasound anomalies yielded 10.4\% abnormal results. This is considerably higher than the yield found in pregnancies at high risk for fetal chromosomal abnormality based on a personal or family history of chromosomal abnormality or prenatal screening by first-trimester combined testing $(5.2 \%$ abnormal NIPT results in the same timeframe, applying the same laboratory protocol; own unpublished data). This is in accordance with the high prevalence of fetal genetic aberrations in the population studied. Chromosomal and subchromosomal genetic aberrations that can be detected by conventional karyotyping are present in 9-19\% of fetuses with single and multiple anomalies, respectively ${ }^{13}$. Clinically relevant submicroscopic CNVs detected by microarray analysis are found in $5-10 \%$ of fetuses with ultrasound anomalies and a normal karyotype ${ }^{1-3}$.

With the present state of technology, NIPT should be able to detect common whole-chromosome aneuploidies with high sensitivity and specificity ${ }^{4}$. However, in this study population, two out of five cases of T13 were not detected by NIPT. Discordant findings could possibly be explained by a low fraction of fetal DNA within these samples, directly affecting the diagnostic 
Table 4 Diagnostic yield of non-invasive prenatal testing (NIPT) and invasive diagnostic genetic testing by quantitative fluorescent polymerase chain reaction (QF-PCR) and chromosomal microarray analysis in 251 pregnancies with ultrasound anomaly

\begin{tabular}{lcc}
\hline & \multicolumn{2}{c}{ Diagnostic yield } \\
\cline { 2 - 3 } $\begin{array}{l}\text { Indication } \\
\text { for genetic testing }\end{array}$ & NIPT & $\begin{array}{c}\text { QF-PCR and } \\
\text { microarray analysis* }\end{array}$ \\
\hline Multiple structural & $7 / 13(53.8)$ & $8 / 13(61.5)$ \\
$\quad$ anomalies & $4 / 57(7.0)$ & $5 / 57(8.8) \dagger$ \\
Structural anomaly & $9 / 58(15.5)$ & $10 / 58(17.2)$ \\
NT $\geq 3.5$ mm & $2 / 73(2.7)$ & $2 / 73(2.7)$ \\
Sonographic marker & $4 / 40(10.0)$ & $5 / 40(12.5)$ \\
IUGR & $0 / 10(0.0)$ & $2 / 10(20.0) \neq$ \\
Other & $26 / 251(10.4)$ & $32 / 251(12.7)$ \\
Total & (Y) & \\
\hline
\end{tabular}

Data are given as $n / N(\%)$. *Yield of prenatal genetic testing if invasive diagnostic testing was performed in all pregnancies in cohort. Parentally inherited copy number variants $<1$ megabase $(\mathrm{Mb})$ classified as most probably benign and not clinically relevant and monogenic aberrations that would only have been detected by targeted DNA testing were not taken into consideration. †Including Case 12: normal NIPT result, in which 16p11.2 610 kilobase gain (susceptibility locus) would have been detected by chromosomal microarray analysis, but (clinically relevant) hypomethylation of KCNQ1OT1 gene resulting in

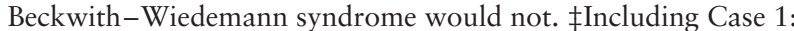
inconclusive NIPT result in which $22 \mathrm{q} 11.21 \sim 2.8 \mathrm{Mb}$ deletion would have been detected by chromosomal microarray analysis despite maternal carrier status. IUGR, intrauterine growth restriction; NT, nuchal translucency thickness.

reliability of NIPT. Research has shown that the fetal fraction is decreased when $\mathrm{T} 13$ is present in the fetus $^{14,15}$. Furthermore, in multiple pregnancies the fetal fraction per fetus is reduced, leading to an increased risk of false-negative results ${ }^{16}$. Unfortunately, in Dutch laboratories, the fraction of fetal DNA is not at present determined when performing NIPT, therefore no additional information regarding fetal fraction was available.

In the presence of sufficient fetal DNA, the resolution and sensitivity of NIPT are limited mainly by sequencing depth $^{6,17}$. It is to be expected that, in due time, technological development will enable non-invasive detection of small pathogenic genetic aberrations, such as microdeletions and microduplications. However, even if the resolution and sensitivity of NIPT were comparable with those of microarray analysis, NIPT cannot be considered a diagnostic test. The present study shows that discordant findings between NIPT and true fetal genotype are unavoidable owing to biological phenomena such as confined placental mosaicism and maternal genetic aberrations.

Although microarray analysis is recommended as the first-tier test for the detection of fetal genetic aberrations in pregnancies with ultrasound anomalies, for some pregnant women and their partners, NIPT represents an acceptable alternative to invasive diagnostic testing. Prospective parents might evaluate differently the benefits and disadvantages of different test modalities depending on many factors, i.e. the value of the information provided by the test, the intention to terminate or continue pregnancy in case of (relevant) fetal genetic aberrations, and acceptability of the risk of a procedure-related miscarriage ${ }^{18}$. Therefore, the choice of a prenatal test should be theirs to make, provided they receive thorough pretest counseling on the characteristics of genetic tests currently available. Pregnant women and their partners should be made fully aware that the information provided by NIPT is inferior to the information provided by invasive diagnostic testing. Furthermore, pregnant women should realize that there is a chance of unlooked-for findings in the form of maternal CNVs.

For pregnancies included in this study, fear of a procedure-related miscarriage and unwillingness to terminate the pregnancy in case of fetal chromosomal abnormality were often noted as reasons for declining invasive diagnostic testing. Unfortunately, the data extracted from medical records were insufficient for further analysis of prospective parents' decision-making. Prospective studies comparing the utility of invasive diagnostic testing with the utility of NIPT for genetic evaluation of pregnancies with ultrasound anomalies should be performed to enable further analysis of prospective parents' decision-making regarding prenatal genetic testing, e.g. preferences, reasons for choosing a certain test modality, informed decision-making, decisional conflict and decision regret.

This study is limited by the fact that, although complete follow-up of pregnancy outcomes was ascertained, diagnostic genetic testing was not performed when sonography or newborn examination did not call for it.

In conclusion, NIPT should not be recommended for genetic evaluation of the etiology of ultrasound anomalies, as both resolution and sensitivity, or negative predictive value, are inferior to those of conventional karyotyping and microarray analysis. Nonetheless, some pregnant women consider NIPT to be an acceptable alternative to invasive diagnostic testing.

\section{ACKNOWLEDGMENTS}

We are grateful to all healthcare professionals who assisted in obtaining complete follow-up of pregnancy outcomes. This study was supported financially by the Foundation for Prenatal Screening in the Nijmegen Region.

\section{REFERENCES}

1. Wapner RJ, Martin CL, Levy B, Ballif BC, Eng CM, Zachary JM, Savage M, Platt LD, Saltzman D, Grobman WA, Klugman S, Scholl T, Simpson JL, McCall K, Aggarwal VS, Bunke B, Nahum O, Patel A, Lamb AN, Thom EA, Beaudet AL, Ledbetter DH, Shaffer LG, Jackson L. Chromosomal microarray versus karyotyping for prenatal diagnosis. N Engl J Med 2012; 367: 2175-2184.

2. Shaffer LG, Rosenfeld JA, Dabell MP, Coppinger J, Bandholz AM, Ellison JW, Ravnan JB, Torchia BS, Ballif BC, Fisher AJ. Detection rates of clinically significant genomic alterations by microarray analysis for specific anomalies detected by ultrasound. Prenat Diagn 2012; 32: 986-995.

3. Hillman SC, McMullan DJ, Hall G, Togneri FS, James N, Maher EJ, Meller CH, Williams D, Wapner RJ, Maher ER, Kilby MD. Use of prenatal chromosomal microarray: prospective cohort study and systematic review and meta-analysis. Ultrasound Obstet Gynecol 2013; 41: 610-620. 
4. Gil MM, Quezada MS, Revello R, Akolekar R, Nicolaides KH. Analysis of cell-free DNA in maternal blood in screening for fetal aneuploidies: updated meta-analysis. Ultrasound Obstet Gynecol 2015; 45: 249-266.

5. Srinivasan A, Bianchi DW, Huang H, Sehnert AJ, Rava RP. Noninvasive detection of fetal subchromosome abnormalities via deep sequencing of maternal plasma. Am J Hum Genet 2013; 92: 167-176.

6. Lo KK, Karampetsou E, Boustred C, McKay F, Mason S, Hill M, Plagnol V, Chitty LS. Limited clinical utility of non-invasive prenatal testing for subchromosomal abnormalities. Am J Hum Genet 2016; 98: 34-44.

7. Faas BHW, de Ligt J, Janssen I, Eggink AJ, Wijnberger LD, van Vugt JM, Vissers L, Geurts van Kessel A. Non-invasive prenatal diagnosis of fetal aneuploidies using massively parallel sequencing-by-ligation and evidence that cell-free fetal DNA in the maternal plasma originates from cytotrophoblastic cells. Expert Opin Biol Ther 2012; 12: S19-S26.

8. Neveling K, Tjwan Thung D, Beulen L, Van Rens-Buijsman W, Gomes I, Van den Heuvel S, Mieloo H, Derks-Prinsen I, Kater-Baats E, Faas BHW. Validation of two-channel sequencing-by-synthesis for noninvasive prenatal testing of fetal whole and partial chromosome aberrations. Prenat Diagn 2016; 36 : $216-223$.

9. Straver R, Sistermans EA, Holstege H, Visser A, Oudejans CB, Reinders MJ. WISECONDOR: detection of fetal aberrations from shallow sequencing maternal plasma based on a within-sample comparison scheme. Nucleic Acids Res 2014; 42: e31.

10. Straver R, Sistermans EA, Reinders MJ. Introducing WISECONDOR for noninvasive prenatal diagnostics. Expert Rev Mol Diagn 2014; 14: 513-515.
11. Kooper AJ, Faas BH, Feenstra I, de Leeuw N, Smeets DF. Best diagnostic approach for the genetic evaluation of fetuses after intrauterine death in first, second of third trimester: QF-PCR, karyotyping and/or genome wide SNP array analysis. Mol Cytogenet 2014; 7: 6.

12. Srebniak MI, Diderich KEM, Govaerts LCP, Joosten M, Riedijk S, Galjaard RJH, Van Opstal D. Types of array findings detectable in cytogenetic diagnosis: a proposal for a generic classification. Eur J Hum Genet 2014; 22: 556-558.

13. Staebler M, Donner C, Van Regemorter N, Duprez L, De Maertelaer V, Devreker F, Avni F. Should determination of the karyotype be systematic for all malformations detected by obstetrical ultrasound? Prenat Diagn 2005; 25: 567-573.

14. Ashoor G, Syngelaki A, Poon LCY, Rezende JC, Nicolaides KH. Fetal fraction in maternal plasma cell-free DNA at 11-13 weeks' gestation: relation to maternal and fetal characteristics. Ultrasound Obstet Gynecol 2013; 41: 26-32.

15. Rava RP, Srinivasan A, Sehnert AJ, Bianchi DW. Circulating fetal cell-free DNA fractions differ in autosomal aneuploidies and monosomy X. Clin Chem 2014; 60: $243-250$.

16. Srinivasan A, Bianchi DW, Liao W, Sehnert AJ, Rava RP. Maternal plasma DNA sequencing: effects of multiple gestation on aneuploidy detection and the relative cell-free fetal DNA per fetus. Am J Obstet Gynecol 2013; 208: S31.

17. Fan HC, Quake SR. Sensitivity of noninvasive prenatal detection of fetal aneuploid from maternal plasma using shotgun sequencing is limited only by counting statistics. PLoS One 2010; 5: e10439.

18. Beulen L, Grutters JP, Faas BHW, Feenstra I, Groenewoud H, Van Vugt JMG, Bekker MN. Women's and healthcare professionals' preferences for prenatal testing. a discrete choice experiment. Prenat Diagn 2015; 35: 549-557.

\section{SUPPORTING INFORMATION ON THE INTERNET}

The following supporting information may be found in the online version of this article:

Table S1 Ultrasound anomaly indicating genetic testing, genetic test results and pregnancy outcome in 251 women who had non-invasive prenatal testing (NIPT)

Table S2 Overview of genetic findings by non-invasive prenatal testing (NIPT) and diagnostic genetic testing in 21 multiple pregnancies with ultrasound (US) anomaly 